\title{
La deconstrucción del concepto de filosofía política en el pensamiento de Hannah Arendt
}

\section{The deconstruction of the concept of political philosophy in Hannah Arendt's thinking}

\author{
ENVER JOEL TORREGROZA LARA
}

Universidad del Rosario, Bogotá

\begin{abstract}
RESUMEN. En vez de formular una nueva teoría política normativa eventualmente aplicable en la práctica, Hannah Arendt deconstruye -O desmantela, como dice ella- presupuestos fundamentales de la tradición filosófica y política occidental, entre los que se destaca creer que la filosofía es capaz de resolver los problemas políticos. El presente artículo examina la forma como Arendt deconstruye este presupuesto, no para lamentarnos de la lejanía entre filosofía y política, como si esta distancia fuese un defecto del pensamiento y no su virtud, sino para comprender que en los asuntos políticos no tenemos que estar esperando respuestas definitivas y salvadoras en prometedoras teorías elaboradas por filósofos.
\end{abstract}

Palabras clave: política, filosofía política, pensamiento político, Arendt, deconstrucción.
ABSTRACT. This article examines the ways in which Hannah Arendt deconstructs —or, as she says, dismantles - one fundamental assumption of the political and philosophical Western tradition: to believe in philosophy as a tool to solve political challenges. Arendt neither formulates a new normative political theory that may eventually be applicable in practice, nor does she regret the distance between philosophy and politics as if such a gap were a thinking flaw rather than a virtue of thought. Still, she seems to suggest that in political affairs no definite answers and solutions can be expected from promising theories elaborated by philosophers.

Key words: politics, political philosophy, political thinking, Arendt, deconstruction.

\section{Introducción: cambiando soluciones por preguntas}

El propósito de este artículo es examinar la forma como Hannah Arendt (1906-1975) deconstruye el concepto de filosofía política dominante en la tradición occidental. Según Arendt, que la filosofía política se haya concebido a sí misma como el arte de fabricar modelos mentales del orden político que merecen ser reproducidos esculpiendo la especie humana como su materia bruta, se debe a su fatal confusión entre acción y producción, entre el actuar y el fabricar, pero también se debe a su voluntad de dominio, a su deseo de cambiar el plural y dinámico mundo de los hombres por un paraíso de es- 
tabilidad metafísica que, de realizarse en la tierra, no sería otra cosa que la infernal consumación de lo inhumano. Por ello, frente a las filosofías políticas preocupadas por cambiar el mundo plural de los hombres mediante la obtención de verdades definitivas que, a fin de cuentas, terminarían por hacernos desechar el pensamiento, Arendt practicará un pensamiento vivo de la política que renuncia a la voluntad de dominio, al mismo tiempo que abandona la voluntad de verdad.

Según la forma platónica de entender la relación entre filosofía y política, la primera debe proveer modelos para la segunda, incluso cuando ninguna de las dos lo quiere: aunque filosofía y política serían incompatibles, ambas se necesitan para sobrevivir. Para Platón, la filosofía es siempre «filosofía política», ya que es en confrontación con la polis como la filosofía se funda a sí misma. Modernamente se afirma que cualquier reflexión tiene «implicaciones políticas», que el ejercicio del pensamiento debe ser útil o no existe sino como respuesta a nuestras necesidades diarias. Cuando Marx desprecia el impulso excéntrico de la filosofía y la reduce a mera ideología, convirtiendo el dinamismo de la actividad del pensamiento en un recetario estático de órdenes descontextualizadas, sigue asumiendo que la filosofía depende de la política, esta vez como un instrumento suyo, puesto que concibe la filosofía como simple epifenómeno de los intereses mundanos del hombre. Que desde Platón a Marx existan filosofías ansiosas de cambiar los hombres, porque no se tolera su desorden, su incapacidad de adaptarse a las perfectas formas de un abstracto e inhumano pathos de justicia intemporal o futura, confirma tanto la esclavitud política de la filosofía política occidental como su inveterado odio cuasi-teológico del mundo de apariencias, de la caverna semi-iluminada en la que moramos los hombres que no queremos ser dioses.

Ante la ruptura del hilo de esta tradición, evidenciada — según Arendten el asenso del totalitarismo, el pensamiento arendtiano desmantela los presupuestos básicos de la filosofía política occidental, no para destruir el pasado sino para otorgarle nuevos significados, reavivando las preguntas fundamentales de la política y destilando el «espíritu original» de los conceptos políticos claves del pensamiento clásico. Mediante metáforas, que es como fluye el pensamiento, Arendt describe, citando a Shakespeare (The Tempest, I, 2), nuestra relación con el pasado: el tiempo es el mar que convierte en tesoros nuestros los restos de un antiguo naufragio.

\section{La política como punto de partida}

Arendt representa en el panorama del pensamiento occidental contemporáneo uno de los esfuerzos más serios, si no el más radical, por pensar la política desde sí misma. Esto implicó para Arendt asumir como punto de partida de su pensamiento justamente aquel lugar del que tradicionalmente muchas filoso- 
fías habían querido tomar distancia en el momento de comenzar sus empeños reflexivos: el mundo común de los hombres. Sin embargo, Arendt no lo hace, como podría muy fácilmente creerse, asumiendo que el pensamiento puede darse mientras estemos completamente inmersos en las tareas cotidianas. La teoría los dos mundos, que nutrió la metafísica occidental durante siglos, aunque falaz, nos enseña de todas formas algo elemental: para pensar requerimos tomar cierta distancia del mundo de las tareas diarias, del trabajo y de la política (Arendt, 2002, 91 y ss.). Arendt no propone una identificación total de las actividades del mundo de la vida con la actividad del pensamiento, como si ya pensáramos por el simple hecho de actuar. Para pensar nos debemos por un tiempo retirar, abriendo una brecha entre el pasado y el futuro (Arendt, 2002, 229). De lo que se trata aquí más bien es de comprender desde un comienzo el pensamiento como una actividad entre otras, que tiene como punto de origen el mundo plural de los hombres, sin que eso signifique de ninguna manera que sea una actividad «cualquiera» fácilmente reemplazable por las demás.

En su obra tardía La vida del espíritu, Arendt distingue el pensamiento de las otras facultades del espíritu: la voluntad y del juicio. Siendo más cercanas al mundo de apariencias y estando directamente relacionadas con fenómenos particulares ubicables en un espacio y un tiempo específicos, la voluntad y el juicio comparten con el pensamiento sus breves retiradas del mundo sólo para volver prontamente a él (Arendt, 2002, 114). Cuando juzgamos permanecemos en el teatro del mundo como espectadores que hacen parte del público plural (Arendt, 2002, 116); en cambio cuando pensamos nos retiramos del teatro para contemplarlo en su ausencia.

La preocupación por la relación entre vita activa y vida del espíritu, de la que el enfrentamiento entre política y filosofía sólo es una parte, atraviesa por completo la obra de Arendt. En La condición humana, Arendt recupera al interior de la vita activa la distinción entre labor, trabajo y acción; distinción que había sido borrada, según ella, por el empeño tradicional en subrayar la oposición entre la mundana actividad humana y el modo de vida del filósofo. El filósofo que consagra su vida a la contemplación prefiere, como diría Sloterdijk hablando del monacato, «huir del mundo», puesto que su morada es otra (Sloterdijk, 2008, 110): es un extranjero como diría Aristóteles (Pol. 1324a16). A pesar de la sobrevaloración moderna del trabajo y la defensa de la vita negotiosa por encima del bios theoretikos de los filósofos, el mundo moderno se caracteriza por un notable desprendimiento del mundo común de los hombres y el consecuente olvido del espacio propio de la política (Arendt, 1993). Así como Heidegger atribuye al dominio de la ciencia concebida como técnica el olvido del ser (Heidegger, 2003), Arendt considera fatal para la experiencia humana moderna la confusión entre praxis y techné, que ha reducido la acción política, valiosa per se - esto es, independientemente de sus resultados - a un hacer productivo que debe ser juzgado por las obras que 
deja tras de sí; si es que la acción no es también reducida, como suele ocurrir en el mundo moderno, junto con el trabajo (poiesis) a mera labor, a simple reproducción cíclica que asegure nuestra supervivencia como especie, acabando con cualquier posibilidad de realización humana singular en medio de la pluralidad (Arendt: 1993). Semejante olvido del mundo plural de los hombres, y del sentido común que le corresponde, coincide, y no por casualidad, con el origen de la tradición dominante en la filosofía moderna.

Mientras que el punto de partida de Descartes y, con él, de buena parte de la filosofía moderna, es la soledad del sujeto pensante como origen in-originado a partir del cual construir la experiencia del mundo, Arendt parte más bien de la patente pluralidad de hombres que habitan la tierra, de lo que en $L a$ vida del espíritu denomina el «mundo de apariencias». A diferencia del Heidegger de Ser y tiempo, quien por razones de diacronía expositiva analiza la coexistencia humana (Mitdasein) después de haber analizado el trato mundano con las cosas, el pensamiento de Arendt comienza asumiendo la pluralidad mundana de nuestra existencia como factum irrecusable y básico con respecto al cual adquieren significado las variadas actividades humanas, incluso aquellas que entendemos como una relativa renuncia a los requerimientos de semejante existencia plural, que es lo que ocurre cuando ocasionalmente nos retiramos del trajín del mundo para pensar.

El establecimiento casi forzado de las relaciones de la aislada res cogitans con sus otros congéneres no constituye en ningún momento un problema para Arendt, puesto que su forma de pensar nos enseña que tal distanciamiento supuestamente «originario» es ficticio. Se trata de una de las más notables «falacias metafísicas», como ella misma la llama: el alejamiento del mundo que provee la actividad del pensamiento nos puede hacer creer que los objetos del pensamiento son más reales que el mundo en el que vivimos (Arendt, 2002, 70). Asumir que el sujeto pensante funda el mundo y no al revés es el resultado de lo que Derrida llamó en otro contexto «borradura del origen» (Derrida, 1971), un movimiento violento mediante el cual el pensamiento olvida su origen impuro, borrando su condición de huella que remite irremediablemente a otras huellas que la anteceden y que carecen, estrictamente hablando, de origen propio.

Mientras que Husserl tuvo que esforzarse denodadamente por explicar la constitución del otro en la experiencia fenomenológica, básicamente por haber comenzado su reflexión con una fenomenología de la percepción, es decir con una consideración, preferentemente visual, de la constitución del mundo de las cosas para el ego (Husserl, 1979); Arendt buscará comprender, en la segunda etapa de su vida intelectual, el lugar del pensamiento y del «yo pensante» en este mundo plural, mucho después de haber explicado nuestra condición humana en la tierra. Arendt parte de las diferencias mundanas constituyentes de las individualidades históricas, haciendo del mutuo aparecerse unos a otros en el espacio horizontal de la pluralidad el principium individua- 
tionis de los hombres (Kristeva, 2000), a diferencia del Heidegger de Ser y tiempo, quien comprende la existencia humana en propiedad como un reconocimiento de su mortalidad, haciendo de la conciencia de la absoluta soledad de la muerte el desencadenante ontológico de la diferencia entre el yo y los otros. Aunque en muchos lugares Arendt indicará que es la condición milagrosa del nacimiento la que permite comprender lo inesperado de las acciones de los hombres (Arendt, 1993, 266), constitutivas éstas del ser de cada hombre ante sus congéneres, lo cierto es que Arendt no tiene la pretensión de convertir en ontología fundamental la comprensión cotidiana de la pluralidad que se articula en el sentido común. Antes bien, Arendt cultiva una fenomenología de la acción política en el marco de la vita activa, lo que le permite desarrollar, en términos más generales, una antropología política que revela la «calidad de la existencia humana» (Zapata, 2006), en lugar de una metafísica política o de una teología política. La política precede a la ontología en Arendt, y no al revés.

\section{Pensar la política desde sí misma}

Para pensar la política desde sí misma, con un pensar vivo, Arendt estima necesario pensarla completamente de nuevo, desconfiando de las construcciones conceptuales de las filosofías y las filosofías políticas acumuladas con el tiempo; esto es, yendo «a las cosas mismas» como ordena la buena fenomenología. Arendt argumenta la necesidad de un nuevo pensar frente al carácter inesperado de los graves acontecimientos que rondaron su experiencia vital (Forti, 2001, 209), acontecimientos que según ella no tienen precedente en la historia de la civilización occidental, y a los que se aproximó en su primera publicación fundamental Los orígenes del totalitarismo.

El interés arendtiano en dar a luz un nuevo pensamiento político - interés plenamente consistente con su comprensión de la acción libre como nacimiento - no se debe identificar sin embargo con los intentos previos de refundación de la filosofía política que encontramos en Marx, Spinoza o Hobbes. Sin duda en Arendt está presente una toma de distancia con respecto a sus maestros, semejante a la de Aristóteles y a la que se le podría aplicar el adagio amicus Plato, sed magis amicus veritas sólo que transformado: «siendo amiga de la filosofía, fue más amiga de la política». La afinidad de Arendt con Aristóteles se acentúa cuando pensamos que para ambos las cuestiones políticas no se pueden resolver mediante demostraciones matemáticas. Pero no hay afinidad ni con Spinoza, para quien la filosofía platónica es rechazable por pecar de inaplicable (lo que pone de manifiesto el deseo de Spinoza de formular una filosofía que se pueda implementar para con ello corregir el curso de la vida política humana, tal y como Hobbes también lo deseó), ni con Marx, quien rechaza la filosofía política previa debido a que esta se dedicó a 
interpretar el mundo de los hombres y no se entregó a su transformación. En realidad, Arendt está más cerca de Maquiavelo, Montesquieu y Tocqueville, tres intérpretes de la política que ella «redescubrió» (Forti, 2001, 111), y quienes parecen haberse empeñado en pensar, como Arendt, «las cosas mismas», el asunto mismo de la política.

El novum que surge en la reconsideración arendtiana de la política desde sí misma no es otra cosa que la ruptura con la voluntad de encontrar una filosofía que tenga efectos prácticos inmediatos o que se pueda traducir en técnicas que permitan solucionar los problemas de convivencia de los hombres. Arendt duda de la necesidad de una filosofía que nos diga qué acciones realizar. Al respecto Arendt afirma:

Si verdaderamente creemos [...] que la pluralidad rige la tierra, entonces hay que modificar el concepto de unidad entre la teoría y la práctica hasta tal punto que sea irreconocible para quienes lo pensaron antes. De hecho, considero que sólo se puede actuar concertadamente y que sólo se puede pensar por sí mismo. Se trata de dos posiciones «existenciales» — por así decirlo enteramente distintas. Y suponer alguna influencia directa de la teoría sobre la acción, en la medida en que la teoría es solamente un objeto del pensar, es decir, desarrollada en el pensamiento, es suponer algo que, de hecho no es ni nunca será así (Arendt, 1995, 141).

A diferencia de Marx, Arendt no cree que el error de los filósofos haya sido el haberse dedicado a interpretar el mundo y no a cambiarlo; antes bien, Arendt defiende la idea contraria: los filósofos se equivocan cuando intentan transformar el mundo, cuando de lo que se deben ocupar es de interpretarlo; algo que no han hecho siempre bien. Según Arendt, no hay que convertir el pensamiento en una antesala de la voluntad, con el fin de justificar falazmente su existencia a partir de una hipotética utilidad intramundana. Abiertamente en contra de Spinoza (como en todo lo demás), quien identificaba voluntad con razón, pero también en contra de Marx y Sartre y todos aquellos que convirtieron, debido a su vocación onírica, la voluntad en un «sustituto del pensamiento» (Arendt, 2002, 234), Arendt se empeña en recuperar la diferencia entre ambas. El pensar se retira del mundo porque hay que protegerlo de la voluntad metafísica de dominio (Arendt, 2008b, 125). Aunque algunos consideran que este acercamiento a Heidegger es inconsistente con su propuesta política (Bernstein, 2000), lo cierto es que se trata de una forma de proteger el mundo de la política de la amenaza latente contenida en la filosofía.

\section{El hilo roto de la tradición}

Una de las dificultades más notables en el ejercicio de interpretación de la obra de Hannah Arendt radica en su abierto rechazo del apelativo «filosofía política» para caracterizar su pensamiento. No se trata de una simple mani- 
festación de humildad; antes bien, semejante rechazo es inherente al proyecto de pensamiento en el que ella se embarca puesto que su punto de partida es una clara toma de distancia con respecto a la tradición metafísica. Tal toma de distancia no consiste en una deliberada renuncia a las construcciones mentales del pasado sino en el reconocimiento de un olvido que describe nuestros tiempos. Así lo reconoce Arendt:

Me he alistado en las filas de aquellos que desde hace ya algún tiempo se esfuerzan por desmontar la metafísica y la filosofía, con todas sus categorías, tal y como las hemos conocido desde sus comienzos en Grecia hasta nuestros días. Tal desmantelamiento sólo es posible si partimos del supuesto de que el hilo de la tradición se ha roto y que no seremos capaces de renovarlo. Desde la perspectiva histórica, lo que en realidad se ha derrumbado es la trinidad romana, que durante siglos unió religión, autoridad y tradición. La pérdida de esta trinidad no anula el pasado, y el proceso de desmantelamiento no es en sí mismo destructivo; se limita a sacar conclusiones de una pérdida que es una realidad y que, como tal, ya no forma parte de la «historia de las ideas», sino de nuestra historia política, de la historia del mundo (Arendt, 2002, 231).

Que la ruptura del hilo de la tradición sea un acontecimiento de la historia política implica que la deconstrucción de las jerarquías categoriales de la metafísica occidental no es producto de una voluntad de ruptura fundada en una supuesta conciencia de superioridad epocal, ni nace de una sistemática negación del pasado ansiosa del advenimiento de un futuro esencialmente mejor. Lo que hace Arendt es simplemente «pensar en lo que hacemos» (Arendt, 1993, 18). En su compilación de ensayos publicada en los años sesenta y titulada Between Past and Future, Arendt hace una concisa descripción del tipo de pensamiento con el que ella asume la ruptura del hilo de la tradición: no le interesa en absoluto «restablecer el hilo roto» ni mucho menos «inventar novedosos sucedáneos»; su pensar es un ejercicio continuado que busca adquirir experiencia de «cómo pensar» y no pretende prescribir «qué hay que pensar ni qué verdades se deben sustentar», puesto que en sus ejercicios de pensamiento «el problema de la verdad permanece en estado latente» (Arendt, 1996, 20). Como señalará Arendt en La vida del espíritu, apoyándose en parte en la interpretación de Eric Weil de la distinción kantiana entre Vernuft y Verstand (Arendt, 2002, 87), el pensamiento a diferencia de la ciencia no está al servicio del conocimiento sino que lo único que procura es otorgar sentido a lo ocurrido: se ocupa del significado, no de la verdad (Arendt, 2002, 86). Por ello Arendt se interesa más en «destilar» de los conceptos políticos tradicionales «su espíritu original». El «espíritu original» de los conceptos clave de la política (libertad, justicia, autoridad, razón, responsabilidad, virtud, poder y gloria) se ha esfumado porque en la elaboración de la filosofía política, por parte de la filosofía y de la ciencia política occidentales, se le dio la espalda — sólo con notables excepciones en Maquiavelo, Tocqueville o Montes- 
quieu, por ejemplo - a la «realidad fenoménica subyacente» a esos conceptos (Arendt, 1996, 21).

Sin embargo, el lugar desde el cual el pensamiento deconstructivo arendtiano reflexiona sobre los conceptos políticos tradicionales se comprende mejor cuando se explica dónde se ha roto el hilo de la tradición, puesto que no se trata únicamente del abandono de la realidad fenoménica que nutrió tales conceptos; abandono que Arendt habría explicado en La condición humana como la alienación moderna del mundo de apariencias, del mundo común y plural de los hombres, gracias a la victoria del homo faber y del animal laborans sobre el homo praxeos. Que el hilo de la tradición se haya roto significa que el pasado ya no tiene autoridad entre nosotros y que nuestro ligazón con él no puede ser restablecida; es decir que la trinidad romana que vinculaba tradición, autoridad y religión se ha derrumbado (Arendt, 1996, 132-135). Para Arendt, la ruptura con el pasado se hizo patente con el asenso del totalitarismo en el siglo XX, pues como acontecimiento traumático representó un reto sin precedentes para el pensamiento occidental al no poderse «aprehender mediante las categorías habituales del pensamiento político» (Arendt, 1996, 32), sin que esto signifique para Arendt que la ruptura con la autoridad haya sido una consecuencia del dominio totalitario y no más bien su antesala (Arendt, 1996, 101).

\section{La diferencia entre filosofía y pensamiento}

Arendt llegó a preferir el apelativo «teórica política» al de «filósofa política» no porque haya querido construir una filosofía política científica alejada de compromisos metafísicos - pues Arendt nunca sugirió siquiera compartir las certezas metafísicas del positivismo-, sino porque sabía que la expresión «filosofía política» podía contener una contradicción en los términos. La filosofía política no es solamente la reflexión sobre los asuntos políticos sino también la expresión del rechazo filosófico de la política (Arendt, 1996, 117, 124). Para Arendt la filosofía política occidental quedó marcada de nacimiento por el desengaño platónico frente a la política. La filosofía política nace como una defensa de la filosofía ante la polis que la desprecia, mediante el recurso inverso de fundar la filosofía en el desprecio de la Ciudad. Ante la condena de Sócrates y ante la visible enemistad entre la polis y la filosofía, Platón intentará mostrar que si bien la filosofía no necesita de la polis, la polis no puede vivir sin la filosofía (Arendt, 2008a, 64 y ss.)

Gracias al mundo romano, que convirtió a Platón en una autoridad, la filosofía política devino en una carta de ruta supuestamente imprescindible para la acción política (Arendt, 1996, 117 y ss.). La filosofía política ha sido tradicionalmente concebida como un ejercicio productor de ideas que se juzgan válidas en virtud de su veracidad y su aplicabilidad al mundo común de 
los hombres. Pero en la medida en que toda teorización, al tematizar las apariencias mediante su desensorización y desespacialización (Arendt, 2002, 98 y ss.), tiende a formular generalidades que borran las diferencias, la teoría política pasa por encima de la pluralidad que es condición de la política, negando a su vez la singularidad de las acciones humanas.

Al comienzo de La vida del Espíritu, Arendt utiliza como epígrafe un pasaje del texto en el que Heidegger piensa la pregunta «¿qué significa pensar?» sin darle por supuesto respuesta concluyente. El pasaje de Heidegger es el siguiente:

El pensar no conduce a un saber como las ciencias. El pensar no produce ninguna sabiduría aprovechable a la vida. El pensar no descifra enigmas del mundo. El pensar no infunde inmediatamente fuerzas para la acción. (Heidegger, 2008, 216)

El fragmento es iluminador no sólo porque nos invita a pensar el pensar sin sus posibles efectos, permitiéndonos distinguir el pensar del teorizar de la ciencia, con el que habitualmente se confunde, sino también porque es una indicación que nos permite encarar el problema de los «efectos» del pensamiento, cuestión siempre contemporánea e ineludible en la medida en que inmersos en el mundo de las apariencias - por usar la expresión de Arendtnos resistimos a todo intento por «salir» del mundo cotidiano con el que vivimos familiarizados. El pensar nos puede resultar extraño y hasta peligroso porque abre terrenos poco familiares ajenos a las urgencias biológicas, productivas o políticas de nuestro hogar terrestre, incitando la relativización misma del suelo que habitualmente pisamos y con ello aterrorizándonos así sea subrepticiamente. Por ese motivo nos podemos ver avocados a sospechar del pensamiento, en la medida en que desmantela edificaciones metafísicas en las que confortablemente habitamos.

Quien crea que tener reservas con respecto a las bondades de la metafísica - en tanto que «huida» del mundo cotidiano y terrestre hacia «terrenos» no perceptibles - es el resultado de una sana actitud crítica exclusivamente moderna, ha olvidado el significado de la risa de la muchacha tracia ante el tropezón de Tales. Coetáneo al pensamiento es su rechazo por parte de quienes ven en el mundo nuestro de cada día urgencias, necesidades y compromisos a los que no se les debe «dar la espalda» persiguiendo actividades inútiles, imprácticas y en general vanas. Cuando al compromiso con la mundaneidad del mundo se lo llama responsabilidad, queda claro que toda divagación sin suelo es un ejercicio irresponsable con el mundo en el que vivimos y que al que primero pone en riesgo es al mismo pensador. Sin embargo, con ello a menudo olvidamos que en esa irresponsabilidad del pensar habitan responsabilidades distintas (que para Arendt nunca son más «altas») que dan «lugar»a un espacio de libertad (análogo al de la acción). Arendt interpreta ese «lugar» del pensamiento como un tiempo: «el tiempo presente» que debe- 
mos conquistar generación tras generación, día tras día, para no diluirnos en el continuum del devenir incansable o en el abismo de un eterno retorno de lo mismo (Arendt, 2002, 224 y ss.).

Para no ubicar la región del pensamiento por fuera del mundo, Arendt describe la actividad del pensamiento como una diagonal resultado del choque perpendicular del pasado y del futuro en un "paralelogramo de fuerzas» (Arendt, 2002, 227). Tal imagen es la apropiada puesto que es la inserción activa del hombre en el curso indiferente del paso del tiempo la que provoca la diferencia entre pasado y futuro. Sin ese activo combatiente, muy lejano de la idea de un objeto que se somete como juguete a las olas del tiempo, no habría tiempo humanamente significativo. El pasado y el futuro le deben por ello su ser al hombre, quien en una lucha para nada inútil sostiene la fugaz plaza del presente, la frágil brecha del tiempo, al atravesar la corriente temporal del cambio perenne y desviarla hacia sí, como foco en el que las fuerzas antagónicas del tiempo conflictivamente convergen, pero del cual fluye el pensamiento, sin final predeterminado. En esta metáfora, la actividad del pensamiento queda «protegida frente al vacío» al permanecer vinculada originariamente al tiempo presente, siempre limitada por el pasado y por el futuro. En este lugar de «calma en medio de la tempestad», efímero refugio de los azotes del tiempo, conquistado día a día por el pensamiento beligerante, habita también el hombre y allí también se libera de la ruina. «En esta brecha entre pasado y futuro - dice Arendt- encontramos nuestro lugar en el tiempo cuando pensamos (Arendt, 2002, 229).

La brecha del tiempo abierta por el hombre, o para ser también aquí heideggerianos, la brecha del tiempo en la que el hombre se abre, es, por supuesto, «coetánea a la existencia del hombre en la tierra» (Arendt, 2002, 229). Arendt piensa este presente humano con otras metáforas también significativas: lo llama «región del espíritu», pero también «sendero pavimentado por el pensar». Arendt define este «sendero» así:

La pequeña y apenas perceptible senda del no-tiempo concedido a los hombres, que deben nacer y morir. Siguiendo este sendero, las cadenas de pensamiento, el recuerdo y la anticipación, salvan aquello que tocan de la ruina del tiempo histórico y biográfico (Arendt, 2002, 229).

Gracias a este sendero, afirma Arendt, parece que los hombres pueden crear obras atemporales que les permiten «trascender su finitud» (Arendt, 2002,230 ), ya que a esa «calma en medio de la tempestad» todas remiten misteriosamente.

La relación del pensador con su presente se debe entender entonces de una manera distinta a la habitual. Más allá de entender al pensador como un intelectual productor de ideas condicionado por su época histórica y su cultura particular, que es el gesto típico de las ciencias sociales, gesto que provoca además discusiones sobre el «compromiso político» del intelectual o sobre su 
capacidad para ser «consecuente», como si el pensamiento humano fuese sólo un instrumento al servicio de la vida o de la política, Arendt valientemente recupera, en el corazón del siglo de la decepción por lo humano, el siglo «antihumanista», el valor del pensar, su significado, más allá de su utilidad científica, técnica, social o económica, y más allá de su impacto político. Que en el mismo siglo Arendt haya también valientemente defendido el sentido de la política y la acción de su fatal confusión con las absorbentes cuestiones sociales y económicas de la labor y el trabajo, no implica que Arendt confundiese, lo que es también fatal, el pensamiento con sus resultados.

El pensador no está eximido del mundo en el que también vive como todos los demás. Como el pensar no se da en el aire - como la burla de Aristófanes sugería al pintar a un Sócrates vagabundo entre las nubes- sino en la Tierra (Arendt, 2002, 227-228), y como la materia del pensar son sus metáforas (Arendt, 2002, 132 y ss.), extraídas todas de nuestros múltiples modos de habitar la Tierra, no existe pensar que no tenga impacto político malgré lui o que no esté expuesto al juicio, en la medida en que deja tras de sí una huella, por lo menos escrita. Se trata del precio que todo pensador debe pagar por su atrevimiento - él también es un héroe tragicómico-: cierta soledad y con ella cierta incomprensión de su actividad. Pero también se trata de la reserva responsable que debe tener el pensador con el mundo: no aventurase en él, sacando consecuencias de sus pensamientos; no intentar moldear su Politeia en los cuerpos de los hombres. Mantener la autonomía de la política con respecto al pensar y viceversa exige que el pensador no quiera regresar a la caverna con ínfulas solares (así como no hay que salir de ella arrastrando cadenas sombrías).

Pensamiento y acción se asemejan en tanto que constituyen espacios liberados de las necesidades y requerimientos del mundo de la labor y del trabajo. Cada pensamiento, como cada acción, tienen sentido en sí mismos independientemente de sus motivaciones o de sus resultados. Si el pensador interrumpe su pensar para retornar al mundo de las apariencias y actuar entre iguales, lo hace como ciudadano, y no como alguien que posee una sabiduría supramundana (o inframundana) digna de asumir el dominio de una Ciudad. El filósofo de la política suele ver en la pluralidad del mundo de apariencias un caos ensombrecido que necesita de orden y luz, por lo que es incapaz de actuar concertadamente, y por lo que su aparición pública termina siendo inevitable objeto de burla. En el entorno de la Ciudad el filósofo debe convertir su pensamiento en juicio (Arendt, 2002, 114 y ss.; Taminiaux, 2007, 47), haciendo parte integral de los espectadores del teatro del mundo y sometiendo sus opiniones a la confrontación con las plurales opiniones de los otros, que le preceden. 


\section{Conclusión: interrogación socrática y la fábula de Aristóteles}

El desmantelamiento de la filosofía política en el pensamiento de Arendt hay que entenderlo como una reconsideración de las preguntas de la filosofía política clásica, liberadas de las múltiples capas acumuladas de interpretación histórica. La tradición de pensamiento puede llegar a ser de nuevo significativa para nosotros si aprovechamos la ruptura del hilo que nos vincula con ella como una oportunidad para reinaugurar el pensar vivo (Arendt, 2002, 39). Para utilizar una metáfora consistente con otro de los campos de su reflexión política, Arendt aprovecha el derrumbe de la filosofía política para revolucionar y refundar el pensamiento político. La reconsideración de la filosofía política clásica nos invita a pensar como un error el irónico distanciamiento platónico de la política que termina por suprimirla, al mismo tiempo que otorga un nuevo significado a la expresión «filosofía política». Como explica Arendt en varios textos compilados póstumamente con el título La promesa de la política, el distanciamiento platónico de la política terminó subordinando el mundo de apariencias, el mundo de la doxa, que es eminentemente político, a la búsqueda del conocimiento, convirtiendo - en el espacio virtual de la filosofía, por supuesto - a la polis en un instrumento de la filosofía (Arendt, 2008a). Ya que la ciudad no acepta con agrado la provocación del filosofar, puesto que éste pone en riesgo la vida de las opiniones y por tanto la pluralidad, sin la cual no hay política, Platón imaginó una ciudad al servicio de la filosofía, sacrificando con ello la política y la libertad (Abensour, 2007). Amante de los justos medios, como buena lectora de Aristóteles, Arendt defiende más bien un punto medio entre los excesos de la sofística y los excesos del platonismo, ambos viciosos. Tal punto medio no es otro que el Sócrates arendtiano: alguien que piensa desde y en la ciudad, pero que no subordina su pensar a las necesidades inmediatas de la polis. El Sócrates de Arendt, aunque idealizado, mantiene una relativa independencia de la ciudad, compensando su deambular citadino con sus retiros ocasionales en el reino del espíritu; a la vez que compensa los excesos del pensamiento, y su inevitable vocación metafísica, retrotrayéndolo al seno de la ciudad, al diálogo con otros en la pluralidad. Reconociéndose en un socratismo, análogo al de Leo Strauss (Cf. Chacón, 2007), Arendt está sin duda del lado de aquellos filósofos contemporáneos que heredaron la deconstrucción como pensar vivo e interrogación constante, abierta por el pensar heideggeriano. Arendt está por ello muy distante de formular una filosofía política normativa, que respondiendo todas las inquietudes, pretenda cerrar la brecha entre el pasado y el futuro abierta por el pensamiento, y en la que el hombre también conquista su humanidad.

Sin embargo, Sócrates también tuvo sus excesos (Dolan, 2000). Para Arendt el que mejor entendió el valor de la retirada del pensamiento fue Aristóteles, quien no sólo pensó como ninguno la diferencia entre acción y pensamiento sino que también huyó oportunamente de Atenas cuando se vio 
amenazado por la ciudad, renunciando a «compartir el destino de Sócrates» (Arendt, 2002, 219). Mientras que Sócrates renunció a su vida entre los hombres por querer mantener la influencia de su pensamiento sobre sus ciudadanos, poniendo en jaque a la polis, Aristóteles habría renunciado a su influencia sobre sus conciudadanos y, con ello, liberado a la polis de incurrir en un segundo crimen contra la filosofía y, de paso, liberado a la filosofía de cometer un segundo crimen contra la Ciudad. Para Arendt el pensador (que aquí sí es un sinónimo del filósofo) es un extranjero, un apátrida que en el momento justo se debe retirar de la polis para no ponerla dramáticamente en cuestión. Retirada que no implica necesariamente irse a otro mundo.

\section{BIBLIOGRAFÍA}

ABEnSOUR, M. (2007): «La lectura arendtiana del mito de la caverna», en Al margen. Hannah Arendt: pensadora en tiempos de oscuridad, No. 21-22.

AREndT, H. (1957): «Was ist Autorität» en Der Monat, VIII, 1956, núm. 89, pp. 29-44; reimpreso en H. Arendt, Fragwürdige Traditionstbestände im politischen Denker der Gegenwart. Vier Essays, Frankfurt, Europäische Verlagsantalt.

- (1993): La condición humana, Barcelona, Paidós.

- (1995): «Arendt sobre Arendt. Un debate sobre su pensamiento», en H. ARENDT, De la historia a la acción, Barcelona, Paidós.

- (1996): Entre el pasado y el futuro, Barcelona, Península.

- (2002): La vida del espíritu, Bs. As., Paidós.

- (2004): Los orígenes del totalitarismo, México, Tecnos.

- (2008a): La promesa de la política, Barcelona, Paidós.

- (2008b): «Martin Heidegger cumple 80 años», en G. ANDERs, H. ARendT, H. JonAS, K. Löwith, L. STRAuSs, Sobre Heidegger. Cinco voces judias, Introducción de F. Volpi, Bs. As., Manantial.

BeIneR, R. (1984): «Action, Natality and Citizenship: Hannah Arendt's Concept of Freedom», en Z. PelCZYNSKI y J. G. Gray (eds.), Conceptions of Liberty in Political Philosophy, Londres, The Athlone Press, pp. 349-375.

BenhabiB, S. (1996): El reluctante modernismo de Hannah Arendt: el diálogo con Martín Heidegger, Valencia, Episteme.

Bernstein, R. (2000): «Arendt on thinking», en D. Villa (ed.), The Cambridge Companion to Hannah Arendt, Cambridge, UP.

Birulés, J. (1996): La especificidad de lo político: Hannah Arendt, Valencia, Episteme.

Canovan, M. (1992): Hannah Arendt. A Reinterpretation of Her Political Thought, Cambridge, Cambridge University Press.

CHACón, R. (2007): «El pensamiento neo-socrático de Hannah Arendt y Leo Strauss», en Al margen. Hannah Arendt: pensadora en tiempos de oscuridad, No. 21-22.

DerRIDA, J. (1971): De la gramatología, México, Siglo XXI.

- (1972): «La différence», en Marges de la philosophie, París, Minuit.

Dolan, F. (2000): «Arendt on philosophy and politics» en: D. VILLA (ed.), The Cambridge Companion to Hannah Arendt, Cambridge, UP. 
Enegrén, A. (1984): La penseé politique de Hannah Arendt, París, PUF.

ForTI, S. (2001): Vida del espíritu y tiempo de la polis, Madrid, Cátedra.

HeIdegger, M. (2003): Ser y tiempo, Madrid, Trotta.

- (2008): ¿Qué significa pensar?, Madrid, Trotta.

Husserl, E. (1979): Meditaciones cartesianas, Madrid, Paulinas.

Kristeva, J. (2000): El genio femenino. 1. Hannah Arendt, Bs. As., Paidós.

McCarthy, M. (1984): «Hannah Arendt and Politics», en Partisan Review, LI, pp. 729-739.

NussBaum, M. (1986): The Fragility of Goodness: Luck and Ethics in Greek Tragedy and Philosophy, Cambridge, Cambridge University Press.

SloterdiJK, P. (2001): Extrañamiento del mundo, Valencia, Pre-Textos.

Taminaux, J. (1987): «Heidegger et Arendt lecteurs d'Aristote», en Les Cahiers de Philosophie, núm. 4, pp. 41-52.

- (1992): La fille de Trace et le penseur professionnel. Arendt et Heidegger, París, Editions Payot.

- (2007): «Hannah Arendt y la deconstrucción de la metafísica», en Al margen. Hannah Arendt: pensadora en tiempos de oscuridad. No. 21-22.

ZapatA, G. (2006): «La condición política en Hannah Arendt», en Papel político, Vol. 11, No. 2. 